\title{
ERP System Implementations vs. IT Projects: Comparison of Critical Success Factors
}

\author{
Christian Leyh and Lars Crenze \\ Technische Universität Dresden, \\ Chair of Information Systems, esp. IS in Manufacturing and Commerce \\ Christian. Leyh@tu-dresden.de
}

\begin{abstract}
The aim of our study was to gain insight into the research field of critical success factors (CSFs) of enterprise resource planning (ERP) implementation projects and of IT projects and to compare the different CSFs. Therefore, we conducted two literature reviews, more specifically systematic reviews of relevant articles in different databases and among several international conference proceedings. Ultimately, we identified 241 relevant papers (111 single or multiple case studies, 82 surveys, and 48 literature reviews or articles from which CSFs can be derived). From these existing studies, we discovered 31 different CSFs for ERP implementation and 24 different CSFs for IT projects. The top two factors identified are equal in both reviews - Top management support and involvement and Project management. However, there are nine CSFs that seem to be relevant only for ERP implementations and two factors that could be found only in the review of IT projects.
\end{abstract}

Keywords: ERP systems, IT projects, implementation, critical success factors, CSF, literature review, comparison.

\section{Introduction}

Today's enterprises are faced with the globalization of markets and fast changes in the economy. In order to be able to cope with these conditions, the use of information and communication systems as well as technology is almost mandatory. Specifically, the adoption of enterprise resource planning (ERP) systems as standardized systems that encompass the actions of whole enterprises has become an important factor in today's business. Therefore, during the last few decades, ERP system software represented one of the fastest growing segments in the software market; indeed, these systems are one of the most important recent developments within information technology [1], [2].

The demand for ERP applications has increased for several reasons, including competitive pressure to become a low-cost producer, expectations of revenue growth, and the desire to re-engineer the business to respond to market challenges. A properly selected and implemented ERP system offers several benefits, such as considerable reductions in inventory costs, raw material costs, lead time for customers, production time, and production costs [3]. The strong demand for ERP applications resulted in a 
highly fragmented ERP market and a great diffusion of ERP systems throughout enterprises of nearly every industry and every size [4], [5]. This multitude of software manufacturers, vendors, and systems implies that enterprises that use or want to use ERP systems must strive to find the "right" software as well as to be aware of the factors that influence the success of the implementation project. Remembering these so-called critical success factors (CSFs) is of high importance whenever a new system is to be adopted and implemented or a running system needs to be upgraded or replaced. Errors during the selection, implementation, or maintenance of ERP systems, incorrect implementation approaches, and ERP systems that do not fit the requirements of the enterprise can all cause financial disadvantages or disasters, perhaps even leading to insolvencies. Several examples of such negative scenarios can be found in the literature (e.g. [6], [7]).

However, it is not only errors in implementing ERP systems that can have negative impact on enterprises; errors within other IT projects (e.g., implementations of BI, CRM or SCM systems, etc.) can be damaging as well. Due to the fast growing and changing evolution of technology, it is especially necessary for enterprises to at least keep in touch with the latest technologies. For example, buzz words like "Cloud computing" or "Software as a Service (SaaS)" can be read throughout managerial magazines very often. Therefore, to cope with implementations of these and other systems it is mandatory for the enterprises to be aware of the CSFs for these IT projects as well.

In order to identify the factors that affect ERP system implementations or IT projects, several case studies, surveys, and even some literature reviews have already been conducted by various researchers. However, a comparison of the factors affecting ERP implementation or IT project success has only rarely been done. To be aware of the differences within the CSFs for ERP and IT projects, it is important for the enterprises to be sure to have / to acquire the "right" employees (project leader, project team members, etc.) with adequate know-how and experience.

To gain insight into the different factors affecting ERP implementation and IT project success, we performed a CSF comparison. We conducted two literature reviews, more specifically, systematic reviews of articles in different databases and among several international conference proceedings. This also served to update the existing reviews by including current literature.

The CSFs reported in this paper were derived from 185 papers dealing with ERP systems and from 56 papers referring to factors affecting IT projects' success. The frequency of the occurrence of each CSF was counted. The aggregated results of these reviews as well as the comparison of the reviews will be presented in this paper.

Therefore, the paper is structured as follows: Within the next section our literature review methodology will be outlined in order to render our reviews reproducible. The third section deals with the results of the literature reviews and the comparison of the reviews. We will point out the factors that are the most important and those that seem to have little influence on the success of ERP implementations and IT projects. Finally, the paper concludes with a summary of the results as well as a critical acclaim for the conducted literature reviews. 


\section{Research Methodology - Literature Review}

Both literature reviews to identify the aforementioned CSFs were performed via several steps, similar to the approach suggested by Webster \& Watson [10]. In general, they were systematic reviews based on several databases that provide access to various IS journals. For the ERP system CSFs, we performed an additional search in the proceedings of several IS conferences. During the review of the ERP papers we identified 185 papers with relevant information concerning CSFs within five databases and among proceedings of five international IS conferences. However the overall procedure for the ERP system review will not be part of this paper. It is described in detail in [8], [9].

The steps of the IT projects' CSF review procedure are presented below. These steps are similar to the ERP CSF review [8], [9]. An overview of the steps is given in Figure 1. However, due to our experience during the first review (duplicates, relevant papers per database and/or proceedings), we reduced the number of databases and did not perform a review among conference proceedings.

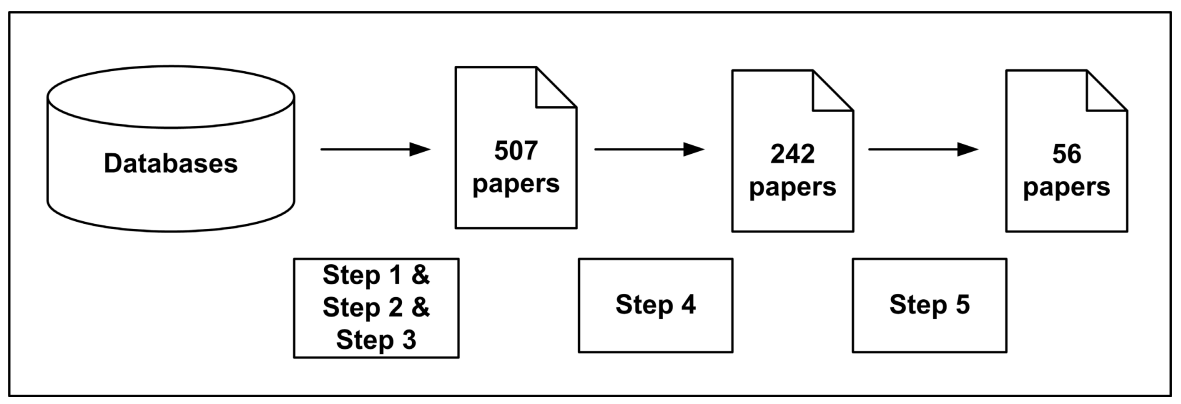

Fig. 1. Progress of the IT projects literature review

Step 1: The first step involved defining the sources for the literature review. For this approach, as mentioned, due to our earlier experience in the review procedure, two databases were identified - "Academic Search Complete" and "Business Source Complete." The first contains academic literature and publications of several academically taught subjects with specific focus on humanities and social sciences. The second covers more practical topics. It contains publications in the English language from 10,000 business and economic magazines and other sources.

Step 2: Within this step, we had to define the search terms for the systematic review. Keywords selected for this search were primarily derived from the keywords supplied and used by the authors of some of the relevant articles identified in a preliminary literature review. It must be mentioned that the search term "CSF" was not used within the Academic Search Complete database since this term is also predominantly used in medical publications and journals. As a second restriction, we excluded the term "ERP" from the search procedure in the Business Source Complete database to focus on IT projects other than ERP projects. However, this restriction could not be used within the first database due to missing functionality. 
Step 3: During this step, we performed the initial search according to steps 1 and 2 and afterwards eliminated duplicates. Once the duplicates were eliminated, 507 articles remained.

Step 4: The next step included the identification of irrelevant papers. During the initial search, we did not apply any restrictions besides the ones mentioned above. The search was not limited to the research field of IS; therefore, papers from other research fields were included in the results as well. These papers had to be excluded. This was accomplished by reviewing the abstracts of the papers and, if necessary, by looking into the papers' contents. In total, this approach yielded 242 papers that were potentially relevant to the field of CSFs for IT projects.

Step 5: The fifth and final step consisted of a detailed analysis of the remaining 242 papers and the identification of the CSFs. Therefore, the content of all 242 papers was reviewed in depth for the purpose of categorizing the identified success factors. Emphasis was placed not only on the wording of these factors but also on their meaning. After this step, 56 relevant papers that suggested, discussed, or mentioned CSFs remained. The results of the analysis of these 56 papers are described in the following section. A list of these papers will not be part of this article but it can be requested from the first author.

\section{Results of the Literature Review - Critical Success Factors Identified}

The goal of the performed reviews was to gain an in-depth understanding of the different CSFs already identified by other researchers. As stated previously, 185 papers that referred to CSFs of ERP implementation projects were identified, as were 56 papers referring to CSFs of IT projects. The identified papers consist of those that present single or multiple case studies, survey results, literature reviews, or CSFs conceptually derived from the chosen literature. They were reviewed again in depth in order to determine the various concepts associated with CSFs. For each paper, the CSFs were captured along with the publication year, the type of data collection used, and the companies (i.e., the number and size) from which the CSFs were derived.

To provide a comprehensive understanding of the different CSFs and their concepts, we described the ERP implementation CSFs in [8] and [9]. There, the detailed definitions of the ERP implementation CSFs can be found. Since most of those CSFs can be matched with CSFs of IT projects (as shown later) we will not describe them within this paper.

\subsection{Critical Success Factors for ERP System Implementations}

Overall, 31 factors (as described in [8], [9]) were identified referring to factors influencing the ERP system implementation success. In most previous literature reviews, the CSFs were grouped without as much attention to detail; therefore, a lower number of CSFs was used (e.g., [3], [11], [12]). However, we took a different approach in our review. For the 31 factors, we used a larger number of categories than 
other researchers, as we expected the resulting distribution to be more insightful. If more broad definitions for some CSFs might be needed at a later time, further aggregation of the categories is still possible.

All 185 papers were published between the years 1998 and 2010. Table 1 shows the distribution of the papers based on publication year. Most of the papers were published between 2004 and 2009. Starting in 2004, about 20 papers on CSFs were published each year. Therefore, a review every two or three years would be reasonable in order to update the results of previously performed literature reviews.

Table 1. Paper distribution of ERP papers

\begin{tabular}{|l|c|c|c|c|c|c|c|}
\hline Year & $\mathbf{2 0 1 0}$ & $\mathbf{2 0 0 9}$ & $\mathbf{2 0 0 8}$ & $\mathbf{2 0 0 7}$ & $\mathbf{2 0 0 6}$ & $\mathbf{2 0 0 5}$ & $\mathbf{2 0 0 4}$ \\
\hline Papers & 6 & 29 & 23 & 23 & 25 & 18 & 23 \\
\hline Year & $\mathbf{2 0 0 3}$ & $\mathbf{2 0 0 2}$ & $\mathbf{2 0 0 1}$ & $\mathbf{2 0 0 0}$ & $\mathbf{1 9 9 9}$ & $\mathbf{1 9 9 8}$ & \\
\hline Papers & 11 & 12 & 5 & 6 & 3 & 1 & \\
\hline
\end{tabular}

The identified CSFs and each factor's total number of occurrences in the reviewed papers are shown in the Appendix in Table 4. Top management support and involvement, Project management, and User training are the three most-named factors, with each being mentioned in 100 or more articles.

Regarding the data collection method, we must note that the papers we analyzed for CSFs were distributed as follows: single or multiple case studies - 95, surveys -55 , and literature reviews or articles in which CSFs are derived from chosen literature -35 .

\subsection{Critical Success Factors for IT Projects}

In the second literature review, 24 factors were identified referring to the success of IT projects. Again, we used a larger number of categories and did not aggregate many of the factors since we had good experience with this approach during our first CSF review. All 56 papers were published between the years 1982 and 2011. Table 2 shows the distribution of the papers based on publication year. Most of the papers were published between 2004 and 2011. It must be stated that some of the papers are older than 15 years. However, we included these papers in the review as well.

Table 2. Paper distribution of IT project papers

\begin{tabular}{|l|c|c|c|c|c|c|c|c|c|}
\hline Year & $\mathbf{2 0 1 1}$ & $\mathbf{2 0 1 0}$ & $\mathbf{2 0 0 9}$ & $\mathbf{2 0 0 8}$ & $\mathbf{2 0 0 7}$ & $\mathbf{2 0 0 6}$ & $\mathbf{2 0 0 5}$ & $\mathbf{2 0 0 4}$ & $\mathbf{2 0 0 3}$ \\
\hline Papers & 4 & 5 & 6 & 6 & 3 & 10 & 4 & 5 & 1 \\
\hline Year & $\mathbf{2 0 0 2}$ & $\mathbf{2 0 0 1}$ & $\mathbf{1 9 9 8}$ & $\mathbf{1 9 9 5}$ & $\mathbf{1 9 9 3}$ & $\mathbf{1 9 8 7}$ & $\mathbf{1 9 8 3}$ & $\mathbf{1 9 8 2}$ & \\
\hline Papers & 2 & 1 & 1 & 2 & 2 & 2 & 1 & 1 & \\
\hline
\end{tabular}


Table 3 shows the results of our review, i.e., the identified CSFs and each factor's total number of occurrences in the reviewed papers. Project management and Top management support are the two most often named factors, with each being mentioned in some 30 or more articles. These factors are followed by Solution fit, Organizational structure, and Resource management, all mentioned in nearly the half of the analyzed articles. As shown in Table 3, due to the smaller number of relevant papers, the differentiation between the separate CSFs is not as clear as with the ERP CSFs. Most differ by only small numbers.

Table 3. IT projects CSFs in rank order based on frequency of appearance in analyzed literature

\begin{tabular}{|l|c|l|c|}
\hline \multicolumn{1}{|c|}{ Factor } & $\begin{array}{c}\text { Number of } \\
\text { instances }\end{array}$ & \multicolumn{1}{|c|}{ Factor } & $\begin{array}{c}\text { Number of } \\
\text { instances }\end{array}$ \\
\hline Project management & $\mathbf{3 1}$ & $\begin{array}{l}\text { Commitment and motivation of } \\
\text { the employees }\end{array}$ & $\mathbf{1 7}$ \\
\hline Top management support & $\mathbf{3 0}$ & Implementation approach & $\mathbf{1 7}$ \\
\hline Organizational structure & $\mathbf{2 6}$ & Communication & $\mathbf{1 5}$ \\
\hline Solution fit & $\mathbf{2 6}$ & Strategy fit & $\mathbf{1 5}$ \\
\hline Resources management & $\mathbf{2 5}$ & Change management & $\mathbf{1 4}$ \\
\hline User involvement & $\mathbf{2 4}$ & Team organization & $\mathbf{1 4}$ \\
\hline Knowledge \& experience & $\mathbf{2 3}$ & Corporate environment & $\mathbf{1 0}$ \\
\hline Budget / available resources & $\mathbf{2 0}$ & Monitoring & $\mathbf{1 0}$ \\
\hline Stakeholder management & $\mathbf{1 9}$ & Project scope & $\mathbf{1 0}$ \\
\hline Leadership & $\mathbf{1 8}$ & Risk management & $\mathbf{8}$ \\
\hline User training & $\mathbf{1 8}$ & Corporate culture & $\mathbf{6}$ \\
\hline Working conditions & $\mathbf{1 8}$ & Legacy systems and IT structure & $\mathbf{3}$ \\
\hline
\end{tabular}

Regarding the data collection method, in this review the papers we analyzed for IT projects' CSFs were distributed as follows: single or multiple case studies - 16, surveys -27 , and literature reviews or articles where CSFs are derived from chosen literature -13 .

\subsection{Comparison of the Critical Success Factors}

As mentioned earlier, we identified 31 CSFs dealing with the success of ERP system implementations and 24 factors affecting IT projects' success. The factors are titled according to the naming used most often in the literature. Therefore, we had to deal with different terms in both reviews. However, most of the CSFs (despite their 
different naming) can be found on both sides. Here, Table 4 in the Appendix provides an overview of the CSF matching.

As shown, there are nine CSFs that occur only in the review of ERP literature. Therefore, these factors are specifically affecting only for ERP implementation projects. However, most of these nine factors are not cited very often, so they seem to be less important than other CSFs mentioned in both reviews. Hence, two of these nine - Business process reengineering (BPR) and ERP system configuration - are in the top 10. Since ERP implementation has a large impact on an enterprise and its organizational structures, BPR is important for adapting the enterprise to appropriately fit the ERP system. On the other side, it is also important to implement the right modules and functionalities of an ERP system and configure them so they fit the way the enterprise conducts business. As not all IT projects have as large an impact on an organization as do ERP implementations, their configuration (or the BPR of the organization's structure) is a less important factor for success.

Within the review of IT project literature, two factors - Resource management and Working conditions - have no match within the ERP implementation CSF list, but here, the first lands in the top five of this review and seems to be an important factor for IT projects' success.

Comparing the top five, it can be found that the two most-often cited factors are the same in both reviews (see Table 3 and Table 4). These top two are followed by different factors in each review. However, it can be stated that project management and the involvement and support of the top management is important for every IT project and ERP implementation. Solution fit (rank \#3) and Organizational fit of the ERP system (rank \#8), which are matched, are both important factors, but are even more important for IT projects. This is also supported by Organizational structure. This factor is \#4 for IT projects but only \#27 for ERP implementation. For IT projects, a fitting structure within the enterprise is important since BPR (as mentioned above) is not a factor for those projects. For ERP implementations, the "right" organizational structure is less important, since BPR is done during almost every ERP implementation project and, therefore, the structure is changed to fit the ERP system.

\section{Conclusion and Limitations}

The aim of our study was to gain insight into the research field of CSFs for ERP implementations and for IT projects and to compare those CSFs. Research on the fields of ERP system implementations and IT projects and their CSFs is a valuable step toward enhancing an organization's chances for implementation success [12]. Our study reveals that several papers, i.e., case studies, surveys, and literature reviews, focus on CSFs. All in all, we identified 185 relevant papers for CSFs dealing with ERP system implementations. From these existing studies, we derived 31 different CSFs. The following are the top three CSFs that were identified: Top management support and involvement, Project management, and User training. For factors affecting IT projects' success, we identified 56 relevant papers citing 24 different CSFs. Here, Project management, Top management support, and Solution fit are the top three CSFs. 
As shown in Table 1 and Table 2, most of the papers in both reviews were published after 2004. Within the ERP paper review, in particular, about 20 or more CFS-papers have been published each year since 2004. Thus, one conclusion suggests that new literature reviews on the CSFs of ERP systems and even on the CSFs for IT projects should be completed every two or three years in order to update the results.

Due to the quickly evolving technology, it becomes more and more important for companies to be up to date and to at least keep in touch with the latest developments. This is also important for smaller and medium-sized enterprises (SMEs). Especially in the ERP market that became saturated in the segment for large companies at the beginning of this century, many ERP manufacturers have shifted focus to the SMEs segment due to low ERP penetration rates within this segment. Therefore, large market potential awaits any ERP manufacturers addressing these markets. This can be transferred to other software and IT solutions as well. To cooperate with larger enterprises with highly developed IT infrastructure, SMEs need to improve their IT systems and infrastructure as well. Therefore, CSF research should also focus on SMEs due to the remarkable differences between large-scale companies and SMEs. ERP implementation projects and IT projects must be adapted to the specific needs of SMEs. Also, the importance of certain CSFs might differ depending on the size of the organization. Thus, we have concluded that an explicit focus on CSFs for SMEs is necessary in future research.

Regarding our literature reviews, a few limitations must be mentioned as well. We are aware that we cannot be certain that we have identified all relevant papers published in journals and conferences since we made a specific selection of five databases and five international conferences, and set even more restrictions while conducting the IT projects' review. Therefore, journals not included in our databases and the proceedings from other conferences might also provide relevant articles. Another limitation is the coding of the CSFs. We tried to reduce any subjectivity by formulating coding rules and by discussing the coding of the CSFs among several independent researchers. Hence, other researchers may code the CSFs in other ways.

\section{References}

1. Deep, A., Guttridge, P., Dani, S., Burns, N.: Investigating factors affecting ERP selection in the made-to-order SME sector. Journal of Manufacturing Technology Management 19(4), 430-446 (2008)

2. Koh, S.C.L., Simpson, M.: Change and uncertainty in SME manufacturing environments using ERP. Journal of Manufacturing Technology Management 16(6), 629-653 (2005)

3. Somers, T.M., Nelson, K.: The impact of critical success factors across the stages of enterprise resource planning implementations. In: Proceedings of the 34th Hawaii International Conference on System Sciences (HICSS 2001), Hawaii, USA, January 3-6 (2001)

4. Winkelmann, A., Klose, K.: Experiences while selecting, adapting and implementing ERP systems in SMEs: a case study. In: Proceedings of the 14th Americas Conference on Information Systems (AMCIS 2008), Paper 257, Toronto, Ontario, Canada, August 14-17 (2008) 
5. Winkelmann, A., Leyh, C.: Teaching ERP systems: A multi-perspective view on the ERP system market. Journal of Information Systems Education 21(2), 233-240 (2010)

6. Barker, T., Frolick, M.N.: ERP implementation failure: A case study. Information Systems Management 20(4), 43-49 (2003)

7. Hsu, K., Sylvestre, J., Sayed, E.N.: Avoiding ERP pitfalls. The Journal of Corporate Accounting \& Finance 17(4), 67-74 (2006)

8. Leyh, C.: Critical success factors for ERP system implementation projects: A literature review. In: Møller, C., Chaudhry, S. (eds.) Advances in Enterprise Information Systems II. CRC Press (2012)

9. Leyh, C.: Critical success factors for ERP system selection, implementation and postimplementation. In: Léger, P.-M., Pellerin, R., Babin, G. (eds.) Readings on Enterprise Resource Planning, ch. 5, pp. 63-77. ERPSim Lab, HEC, Montreal (2011)

10. Webster, J., Watson, R.T.: Analyzing the past, preparing the future: Writing a literature review. MIS Quarterly 26(2), 13-23 (2002)

11. Loh, T.C., Koh, S.C.L.: Critical elements for a successful enterprise resource planning implementation in small-and medium-sized enterprises. International Journal of Production Research 42(17), 3433-3455 (2004)

12. Finney, S., Corbett, M.: ERP implementation: A compilation and analysis of critical success factors. Business Process Management Journal 13(3), 329-347 (2007)

\section{Appendix}

Table 4. Matching of the identified CSFs (CSFs in rank order based on frequency of appearance in analyzed literature)

\begin{tabular}{|c|c|c|c|}
\hline $\begin{array}{c}\text { Rank } \\
\text { [Number of } \\
\text { instances] }\end{array}$ & $\begin{array}{l}\text { CSFs for ERP system } \\
\text { implementations }\end{array}$ & CSFs for IT projects & $\begin{array}{c}\text { Rank } \\
\text { [Number of } \\
\text { instances] }\end{array}$ \\
\hline $\begin{array}{c}1 \\
{[128]}\end{array}$ & $\begin{array}{l}\text { Top management support and } \\
\text { involvement }\end{array}$ & Top management support & $\begin{array}{c}2 \\
{[30]}\end{array}$ \\
\hline $\begin{array}{c}2 \\
{[104]}\end{array}$ & Project management & Project management & $\begin{array}{c}1 \\
{[31]}\end{array}$ \\
\hline $\begin{array}{c}3 \\
{[99]}\end{array}$ & User training & User training & $\begin{array}{c}10 \\
{[18]}\end{array}$ \\
\hline $\begin{array}{c}4 \\
{[86]}\end{array}$ & Change management & Change management & $\begin{array}{c}17 \\
{[14]}\end{array}$ \\
\hline $\begin{array}{c}5 \\
{[85]}\end{array}$ & Balanced project team & Team organization & $\begin{array}{c}17 \\
{[14]}\end{array}$ \\
\hline $\begin{array}{c}6 \\
{[83]}\end{array}$ & Clear goals and objectives & Project scope & $\begin{array}{c}19 \\
{[10]}\end{array}$ \\
\hline $\begin{array}{c}7 \\
{[78]}\end{array}$ & Communication & Communication & $\begin{array}{c}15 \\
{[15]}\end{array}$ \\
\hline
\end{tabular}




\begin{tabular}{|c|c|c|c|}
\hline $\begin{array}{c}8 \\
{[77]}\end{array}$ & $\begin{array}{l}\text { Organizational fit of the ERP } \\
\text { system }\end{array}$ & Solution fit & $\begin{array}{c}3 \\
{[26]}\end{array}$ \\
\hline $\begin{array}{c}8 \\
{[77]}\end{array}$ & ERP system configuration & No match & \\
\hline $\begin{array}{c}10 \\
{[73]}\end{array}$ & Business process reengineering & No match & \\
\hline \multirow[t]{2}{*}{$\begin{array}{c}11 \\
{[68]}\end{array}$} & $\begin{array}{l}\text { Involvement of end-users and } \\
\text { stakeholders }\end{array}$ & User involvement & $\begin{array}{c}6 \\
{[24]}\end{array}$ \\
\hline & & Stakeholder management & $\begin{array}{c}9 \\
{[19]}\end{array}$ \\
\hline $\begin{array}{c}12 \\
{[62]}\end{array}$ & External consultants & No match & \\
\hline $\begin{array}{c}13 \\
{[53]}\end{array}$ & Project champion & Leadership & $\begin{array}{c}10 \\
{[18]}\end{array}$ \\
\hline $\begin{array}{c}13 \\
{[53]}\end{array}$ & IT structure and legacy systems & Legacy systems and IT structure & $\begin{array}{l}24 \\
{[3]}\end{array}$ \\
\hline $\begin{array}{c}15 \\
{[48]}\end{array}$ & $\begin{array}{l}\text { Vendor relationship and } \\
\text { support }\end{array}$ & No match & \\
\hline $\begin{array}{c}16 \\
{[47]}\end{array}$ & Skills, knowledge, and expertise & Knowledge \& experience & $\begin{array}{c}7 \\
{[23]}\end{array}$ \\
\hline $\begin{array}{c}17 \\
{[42]}\end{array}$ & $\begin{array}{l}\text { ERP system acceptance / } \\
\text { resistance }\end{array}$ & $\begin{array}{l}\text { Commitment and motivation of } \\
\text { employees }\end{array}$ & $\begin{array}{c}13 \\
{[17]}\end{array}$ \\
\hline $\begin{array}{c}18 \\
{[41]}\end{array}$ & $\begin{array}{l}\text { Project team leadership / } \\
\text { empowered decision makers }\end{array}$ & Leadership & $\begin{array}{c}10 \\
{[18]}\end{array}$ \\
\hline $\begin{array}{c}19 \\
{[39]}\end{array}$ & $\begin{array}{l}\text { Vendor's tools and } \\
\text { implementation methods }\end{array}$ & Implementation approach & $\begin{array}{c}13 \\
{[17]}\end{array}$ \\
\hline $\begin{array}{c}20 \\
{[38]}\end{array}$ & $\begin{array}{l}\text { Monitoring and performance } \\
\text { measurement }\end{array}$ & Monitoring & $\begin{array}{c}19 \\
{[10]}\end{array}$ \\
\hline $\begin{array}{c}21 \\
{[34]}\end{array}$ & Data accuracy & No match & \\
\hline $\begin{array}{c}22 \\
{[33]}\end{array}$ & Available resources & Budget / available resources & $\begin{array}{c}8 \\
{[20]}\end{array}$ \\
\hline $\begin{array}{c}23 \\
{[31]}\end{array}$ & Organizational culture & Corporate culture & $\begin{array}{l}23 \\
{[6]}\end{array}$ \\
\hline $\begin{array}{c}24 \\
{[23]}\end{array}$ & ERP system tests & No match & \\
\hline
\end{tabular}




\begin{tabular}{|c|c|c|c|}
\hline $\begin{array}{c}25 \\
{[22]}\end{array}$ & Troubleshooting & Risk management & $\begin{array}{l}22 \\
{[8]}\end{array}$ \\
\hline $\begin{array}{c}26 \\
{[21]}\end{array}$ & Environment & Corporate environment & $\begin{array}{c}19 \\
{[10]}\end{array}$ \\
\hline $\begin{array}{c}27 \\
{[17]}\end{array}$ & Organizational structure & Organizational structure & $\begin{array}{c}3 \\
{[26]}\end{array}$ \\
\hline $\begin{array}{c}28 \\
{[16]}\end{array}$ & Interdepartmental cooperation & No match & \\
\hline $\begin{array}{c}28 \\
{[16]}\end{array}$ & Company's strategy / strategy fit & Strategy fit & $\begin{array}{c}15 \\
{[15]}\end{array}$ \\
\hline $\begin{array}{c}30 \\
{[15]}\end{array}$ & Use of a steering committee & No match & \\
\hline \multirow{3}{*}{$\begin{array}{c}31 \\
{[8]}\end{array}$} & Knowledge management & No match & \\
\hline & No match & Resource management & $\begin{array}{c}5 \\
{[25]}\end{array}$ \\
\hline & No match & Working conditions & $\begin{array}{c}10 \\
{[18]}\end{array}$ \\
\hline
\end{tabular}

